
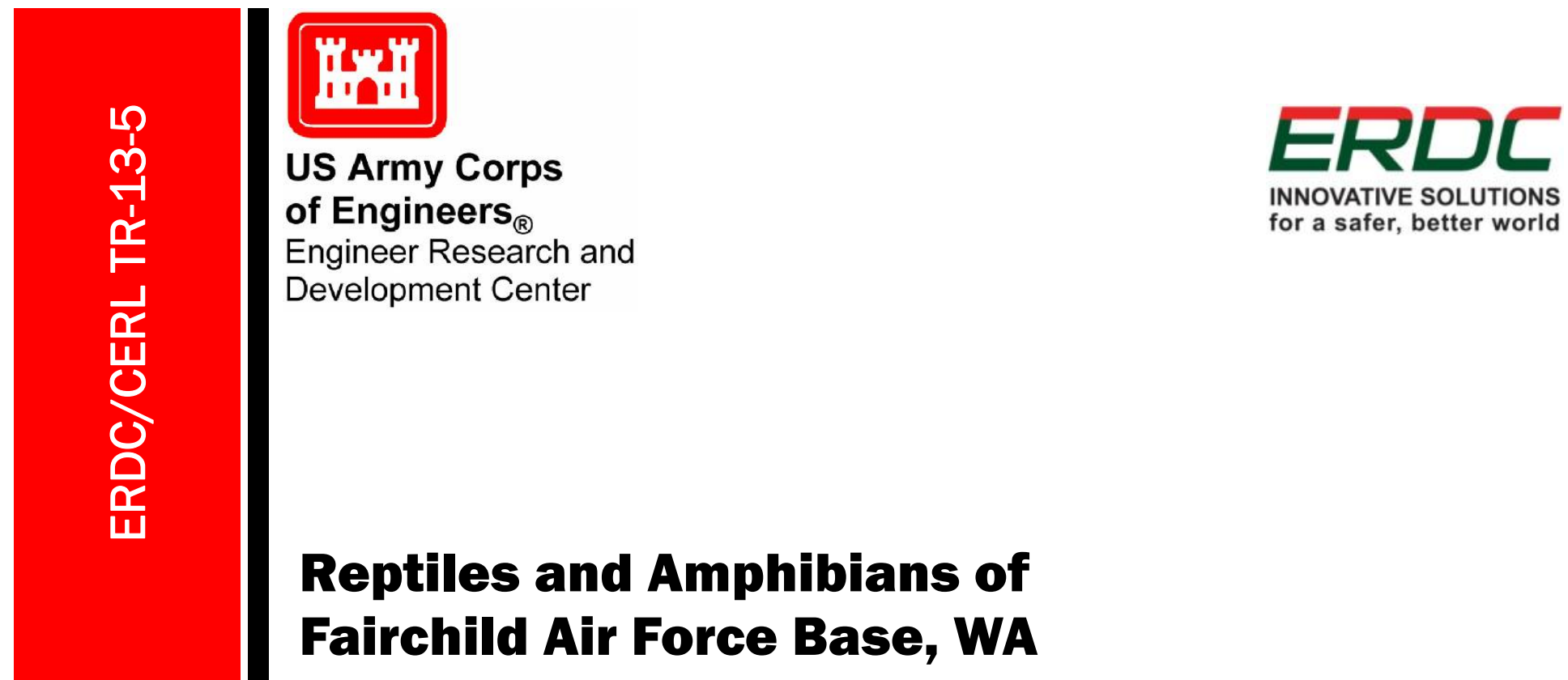

INNOVATIVE SOLUTIONS for a safer, better world

Jinelle H. Sperry

May 2013
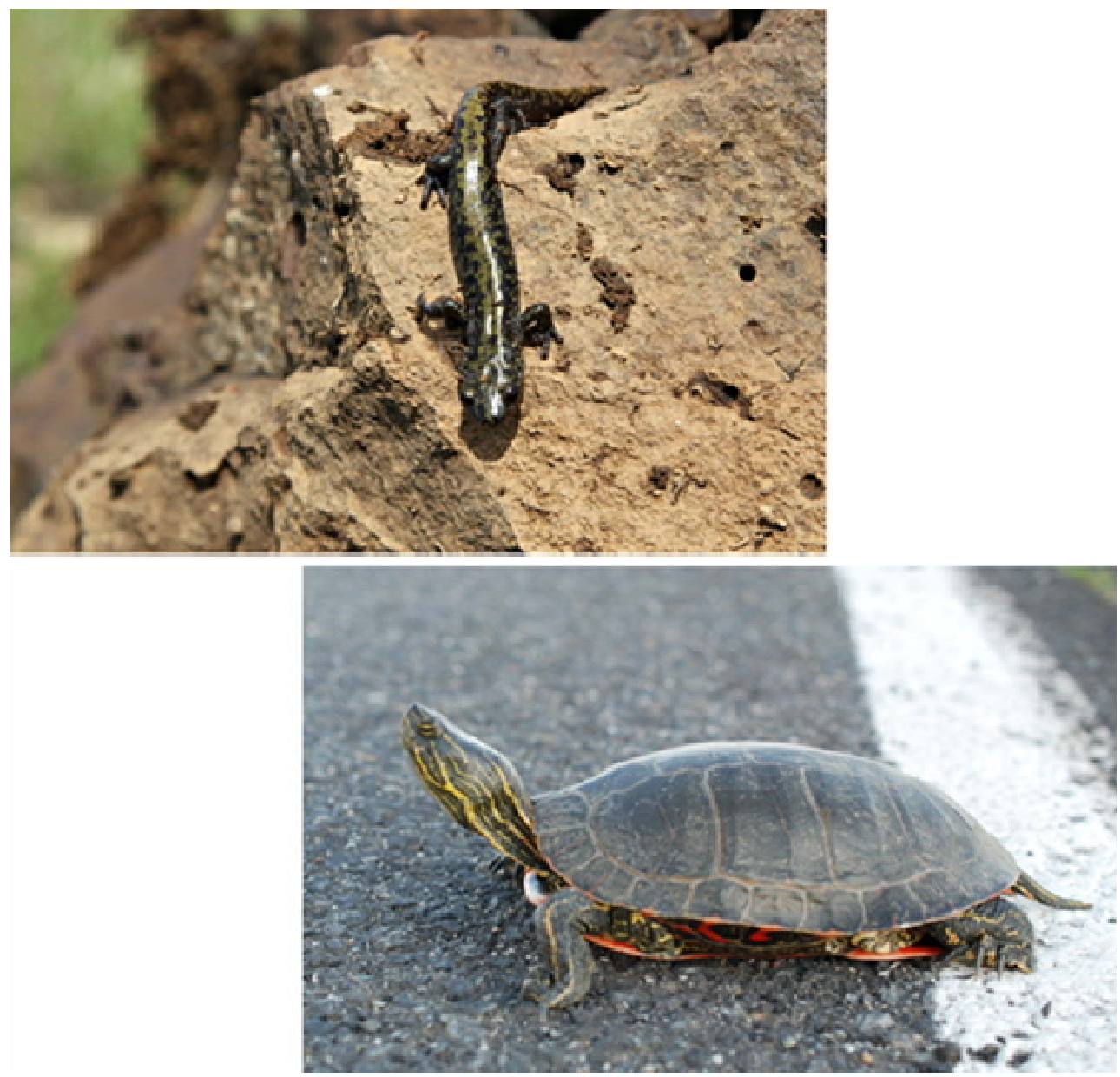
The US Army Engineer Research and Development Center (ERDC) solves the nation's toughest engineering and environmental challenges. ERDC develops innovative solutions in civil and military engineering, geospatial sciences, water resources, and environmental sciences for the Army, the Department of Defense, civilian agencies, and our nation's public good. Find out more at www.erdc.usace.army.mil.

To search for other technical reports published by ERDC, visit the ERDC online library at http://acwc.sdp.sirsi.net/client/default. 


\section{Reptiles and Amphibians of Fairchild Air Force Base, WA}

Jinelle H. Sperry

Construction Engineering Research Laboratory (CERL)

US Army Engineer Research and Development Center 2902 Newmark Dr.

Champaign, IL 61822-1076

Final Report

Approved for public release; distribution is unlimited.

Prepared for Headquarters, US Army Corps of Engineers

Washington, DC 20314-1000 


\section{Abstract}

Many reptile and amphibian (collectively termed "herpetofauna") populations are declining at a precipitous rate. Globally, nearly $30 \%$ of herpetofauna are considered endangered or at risk of extinction. Department of Defense (DoD) installations likely serve as refuges of intact critical habitat for herpetofaunal species, as they do for many other taxa. As more herpetofaunal species become a conservation concern, it becomes increasingly important for DoD land managers to document the species that currently exist on their lands and, through proactive management, avoid potential conflicts between conservation measures and military training. The onus for the protection and long-term population viability of threatened and endangered herpetofaunal species will likely fall in the hands of the installations themselves and will depend on installation management practices. The first step in developing a process to successfully manage herpetofaunal species is to survey their populations on DoD installations. This work surveyed herpetofaunal populations on Fairchild Air Force Base and extrapolated guidelines for species management from the survey results.

DISCLAIMER: The contents of this report are not to be used for advertising, publication, or promotional purposes. Citation of trade names does not constitute an official endorsement or approval of the use of such commercial products. All product names and trademarks cited are the property of their respective owners. The findings of this report are not to be construed as an official Department of the Army position unless so designated by other authorized documents. 


\section{Table of Contents}
Abstract
ii

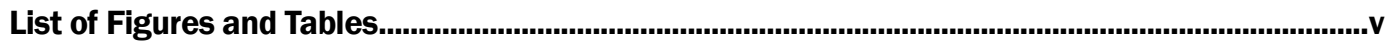
Preface .....................................................................................................................................................vii

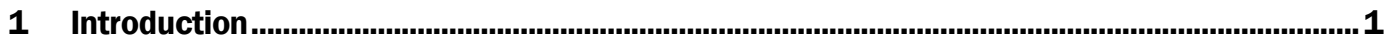

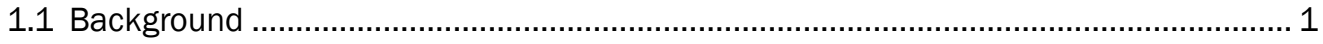

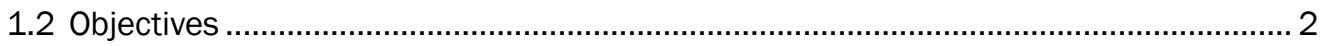

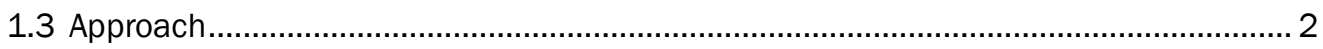

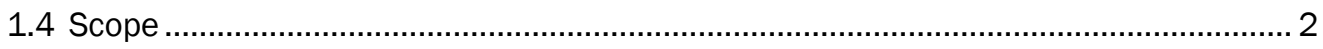

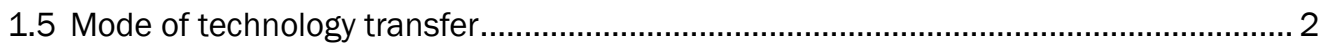

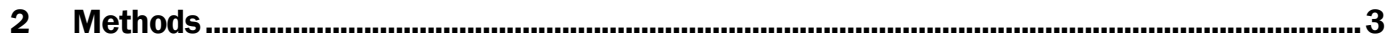

2.1 Survey locations and potential species .............................................................. 3

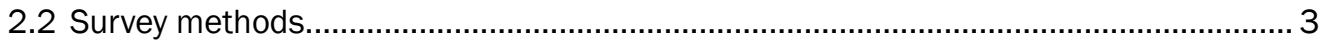

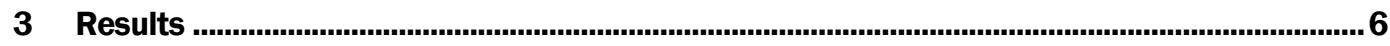

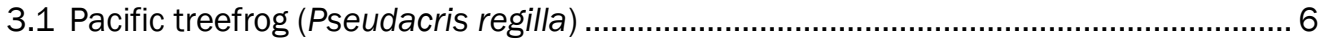

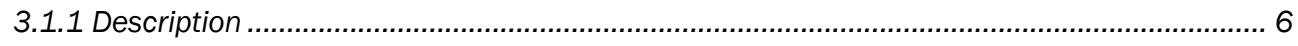

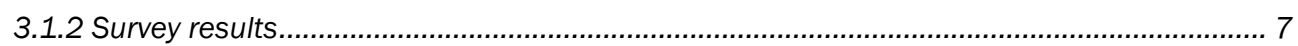

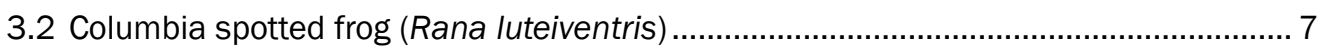

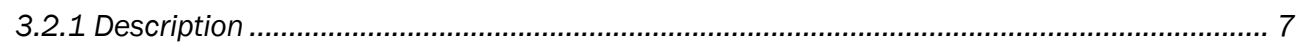

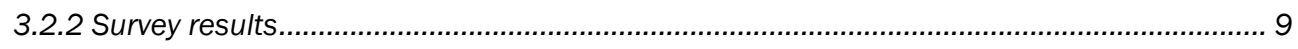

3.3 Western terrestrial garter snake (Thamnophis elegans) ........................................ 9

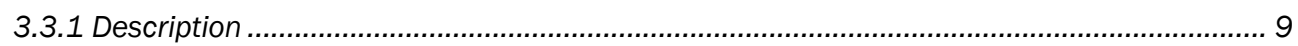

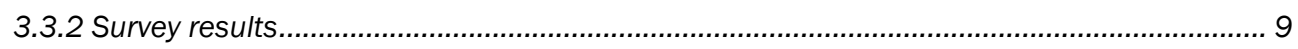

3.4 Valley (common) garter snake (Thamnophis sirtalis) ........................................... 11

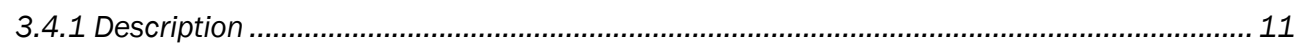

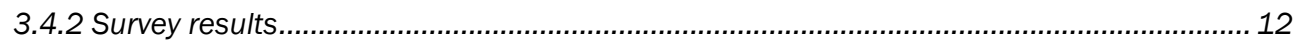

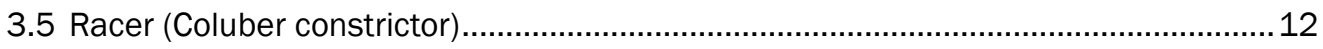

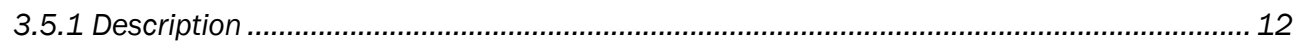

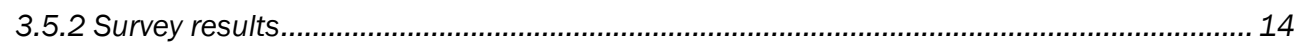

3.6 Long-toed salamander (Ambystoma macrodactylum) ......................................... 15

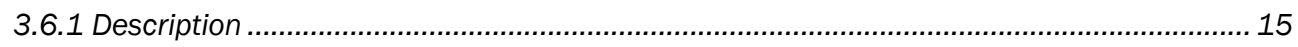

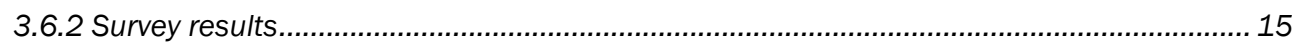

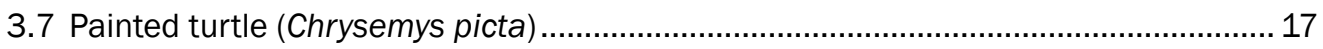

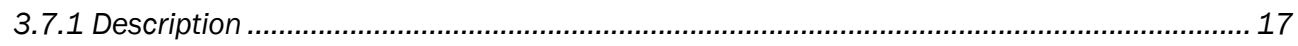

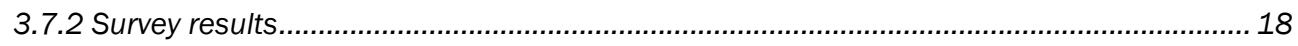

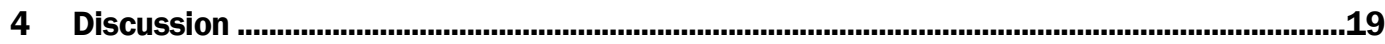

5 Conclusions and Recommendations ....................................................................................21

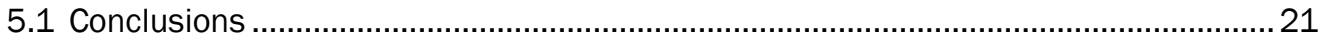

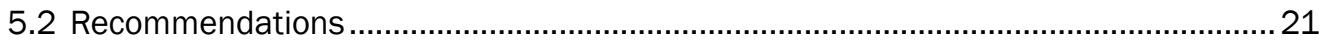




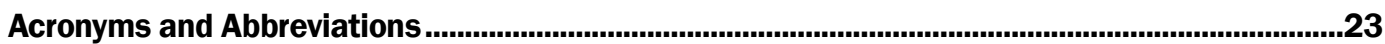

References ...................................................................................................................................................24

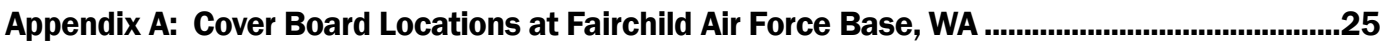

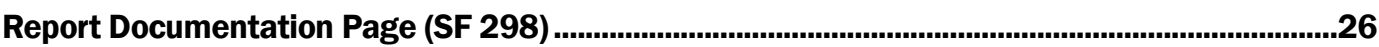




\section{List of Figures and Tables}

\section{Figures}

1 Herpetological survey areas at FAFB. Light green represents forested habitats, green represents shrublands, brown represents semi-desert (scrub-herb) habitats, blue represents wetland areas/vegetation, and grey indicates developed areas

2 Pacific treefrog at FAFB.............................................................................................

3 Pacific treefrog detections (red circles) at FAFB. Light green represents forested habitats, green represents shrublands, brown represents semi-desert (scrubherb) habitats, blue represents wetland areas/vegetation, and grey indicates developed areas 8

4 Columbia spotted frog at FAFB. 8

5 Columbia spotted frog detections (red circles) at FAFB. Light green represents forested habitats, green represents shrublands, brown represents semi-desert (scrub-herb) habitats, blue represents wetland areas/vegetation, and grey indicates developed areas

6 Western terrestrial garter snake at FAFB

7 Western terrestrial garter snake detections (red circles) at FAFB. Light green represents forested habitats, green represents shrublands, brown represents semi-desert (scrub-herb) habitats, blue represents wetland areas/vegetation, and grey indicates developed areas

8 Valley garter snake at FAFB.

9 Valley garter snake (red circles) at FAFB. Light green represents forested habitats, green represents shrublands, brown represents semi-desert (scrubherb) habitats, blue represents wetland areas/vegetation, and grey indicates

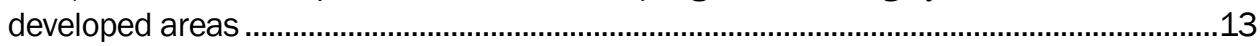

10 Racer at FAFB

11 Racer detections (red circles) at FAFB. Light green represents forested habitats, green represents shrublands, brown represents semi-desert (scrub-herb) habitats, blue represents wetland areas/vegetation, and grey indicates developed areas

12 Long-toed salamander at FAFB

13 Long-toed salamander detections (red circles) at FAFB. Light green represents forested habitats, green represents shrublands, brown represents semi-desert (scrub-herb) habitats, blue represents wetland areas/vegetation, and grey indicates developed areas

14 Painted turtle at FAFB ....................................................................................................

15 Bright red markings on plastron of Painted turtle at FAFB ................................................. 17

16 Painted turtle detections (red circles) at FAFB. Light green represents forested habitats, green represents shrublands, brown represents semi-desert (scrubherb) habitats, blue represents wetland areas/vegetation, and grey indicates developed areas 


\section{Tables}

1 Herpetofaunal species and associated state and Federal conservation status with the potential to be found on FAFB, as determined through range maps ........................ 5

A1 Cover board locations at FAFB .............................................................................................25 


\section{Preface}

This study was conducted for Fairchild Air Force Base via Military Interdepartmental Purchase Request (MIPR) No. F1X3011187G001. The technical monitor was Steven Selser, FAFB Natural and Cultural Resources Manager.

This work was conducted by the Ecological Processes Branch (CN-N), Installations Division (CN), Construction Engineering Research Laboratory (CERL), Engineer Research and Development Center (ERDC). The CERL principal investigator was J inelle H. Sperry. William D. Meyer is Chief, CEERD-CN-N, and Michelle J . Hanson is Chief, CEERD-CN. The associated Technical Director was Alan Anderson, CEERD-CV-T. The Director of ERDC-CERL is Dr. Ilker R. Adiguzel.

CERL is an element of ERDC, US Army Corps of Engineers. The Commander and Executive Director of ERDC is COL Kevin J. Wilson, and the Director of ERDC is Dr. J effery P. Holland. 


\section{Introduction}

\subsection{Background}

Many reptile and amphibian (collectively termed "herpetofauna") populations are declining at a precipitous rate. Globally, nearly 30\% of herpetofauna are considered endangered or at risk of extinction (IUCN 2011). Although a relatively small percentage of US herpetofaunal species are currently listed as threatened or endangered, that number is likely to increase. In fact, a recent petition was filed with the US Fish and Wildlife Service (USFWS) to list an additional 53 amphibians and reptiles under the Endangered Species Act.

Department of Defense (DoD) installations likely serve as refuges of intact critical habitat for herpetofaunal species, as they do for many other taxa. As more herpetofaunal species become a conservation concern, it becomes increasingly important for DoD land managers to document the species that currently exist on their lands and, through proactive management, avoid potential conflicts between conservation measures and military training. The decline of herpetofaunal populations is thought to be the result of a variety of factors including habitat loss/ degradation, overutilization for the pet trade, disease, introduced species, and environmental contaminants (Gibbons et al. 2000, Stuart et al. 2004). Other factors that contribute to population declines, such as collection for the pet trade, are also likely lessened on military lands due to the restrictions on public access.

Consequently, the onus for the protection and long-term population viability of threatened and endangered herpetofaunal species will likely fall in the hands of the installations themselves and will depend on installation management practices. The first step in developing a process to successfully manage these herpetofaunal species is to survey their populations on DoD installations. This work was undertaken to survey herpetofaunal populations on Fairchild Air Force Base (FAFB) and to provide guidelines for species management. 


\subsection{Objectives}

The objectives of this work were to perform surveys of herpetofaunal populations on FAFB, and to use the results of those surveys to provide guidelines for species management.

\subsection{Approach}

Herpetofaunal surveys were conducted at FAFB on 1- 11 May, 8- 14 J une, and 16- 20 J uly 2012. General survey methods included the use of timed aural surveys, automated call recorders, timed visual surveys, dip netting, road surveys and cover boards. The collected data were compiled, summarized, and analyzed; conclusions were draw; and recommendations were formulated to provide guidelines for species management.

\subsection{Scope}

Although this work focused on FAFB herpetofaunal populations, the guidelines for management of these species developed from those surveys may find broader application on other similar DoD installations.

\subsection{Mode of technology transfer}

This report will be made accessible through the World Wide Web (WWW) at URLs:

http://www.cecer.army.mil

http://libweb.erdc.usace.army.mil 


\section{Methods}

\subsection{Survey locations and potential species}

FAFB is a 4500 acre installation located in Spokane County in eastern Washington State. FAFB is located within the Columbia Plateau Ecoregion (USEPA 2012; Omernik 1987) and is dominated by shrub-steppe and grassland communities. Herpetological survey efforts were focused on the unimproved 1400 acres in the northeast corner and southern portion of the base. Within the unimproved areas, increased emphasis was placed on wetland areas where amphibians were more likely to be found. Although there are no defined, natural stream courses on the installation, seasonal runoff accumulates in depressions and creates a myriad of wetland areas, particularly in the southern half of the installation (FAFB 2011). For reporting purposes, the southern portion of the installation was divided into four areas, generally based on a bow hunting areas map provided to survey personnel (Figure 1).

Table 1 lists herpetofaunal species with the potential to be found on FAFB, as determined through range maps (Stebbins 2003). No species with a potential to be found on FAFB have Federal conservation status. Only one species, the Northern leopard frog (Rana pipiens), has Washington State endangered status. Two species, the Western (boreal) toad (Bufo boreas) and the Columbia spotted frog (Rana luteiventris), are listed as candidate species for the state of Washington.

\subsection{Survey methods}

Herpetofaunal surveys were conducted at FAFB on 1- 11 May, 8- 14 J une, and 16- 20 J uly, 2012. Timing of surveys was intended to coincide with amphibian mate calling, free swimming larvae, and metamorph emergence, respectively. General survey methods included the use of timed aural surveys, automated call recorders, timed visual surveys, dip netting, road surveys, and cover boards. Survey methods followed protocols outlined in Heyer et al. (1994). To survey for amphibian mate calling, timed aural surveys were conducted approximately 1 hour before and 2 hours after sunset. Aural surveys were primarily conducted during the May survey. 


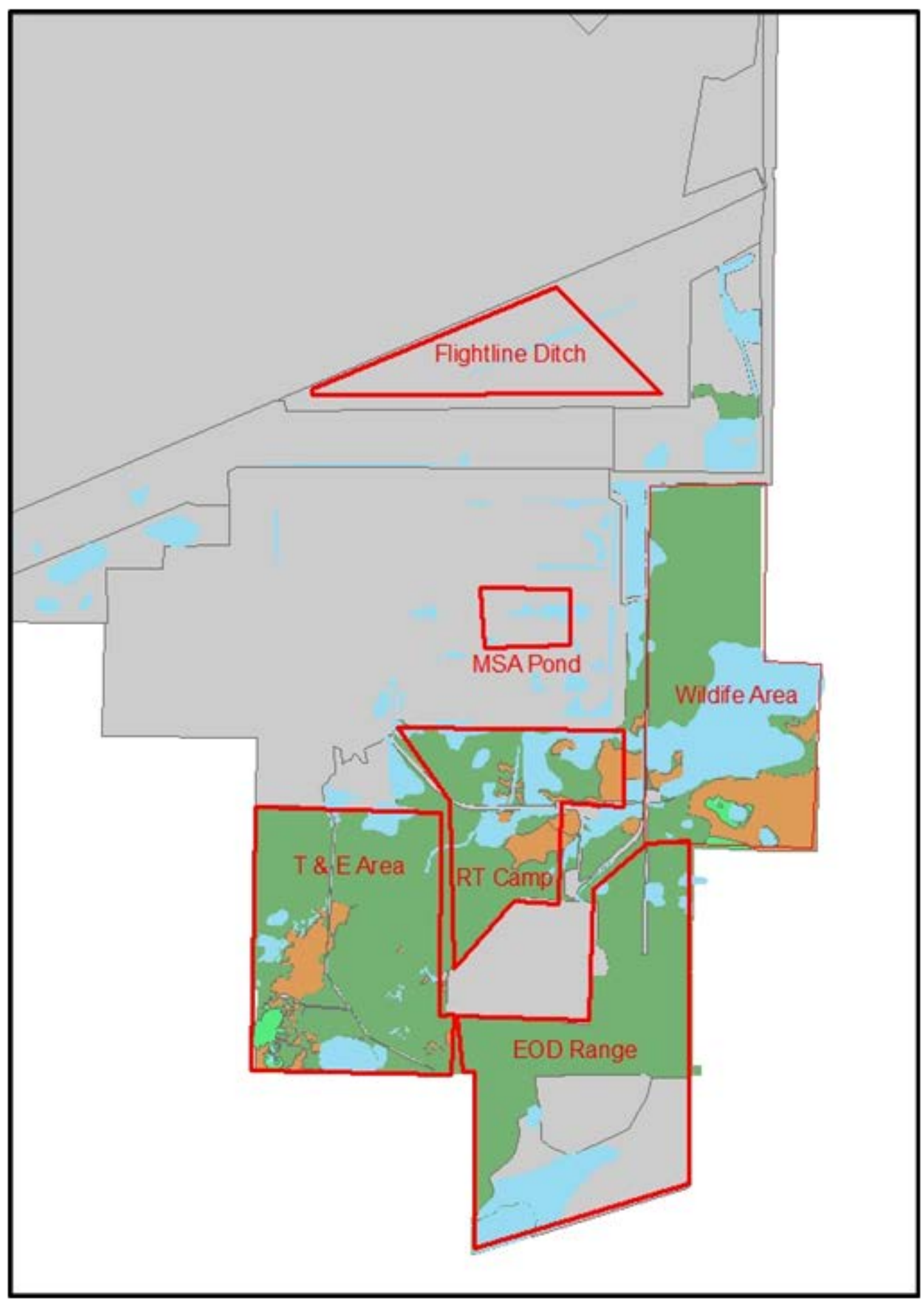

Figure 1. Herpetological survey areas at FAFB. Light green represents forested habitats, green represents shrublands, brown represents semi-desert (scrub-herb) habitats, blue represents wetland areas/vegetation, and grey indicates developed areas. 
Table 1. Herpetofaunal species and associated state and Federal conservation status with the potential to be found on FAFB, as determined through range maps.

\begin{tabular}{|l|l|l|l|}
\hline Common Name & Latin Name & State Rank & Federal Status \\
\hline Tiger Salamander & Ambystoma tigrinum & Monitor (S3) & \\
\hline Great Basin Spadefoot Toad & Scaphiopus intermontanus & None (S5) & \\
\hline Western (Boreal) Toad & Bufo boreas & Candidate (S3S4) & Under Review \\
\hline Pacific treefrog & Hyla (Pseudacris) regilla & None (S5) & \\
\hline Bullfrog & Rana catesbeiana & SE* (Introduced) & \\
\hline Columbia spotted frog & Rana luteiventris & Candidate (S4) & Species of Concern \\
\hline Northern leopard frog & Rana pipiens & Endangered (S1) & \\
\hline Central Long-toed salamander & Ambystoma macrodactylum & None (S5) & \\
\hline Painted turtle & Chrysemys picta & None (S5) & \\
\hline (Pigmy) Short-horned lizard & Phrynosoma douglassii & None (S3) & \\
\hline Western (Skilton's) skink & Eumeces skiltonianus & None (S5) & \\
\hline Northern alligator lizard & Elgaria coerulea & None (S5) & \\
\hline Rubber boa & Charina bottae & None (S4) & \\
\hline (Western yellow-bellied) racer & Coluber constrictor & None (S5) & \\
\hline (Great basin) Gopher snake & Pituophis melanoleucus & None (S5) & \\
\hline Valley garter snake & Thamnophis sirtalis fitchi & None (S5) & \\
\hline Western terrestrial (wandering) garter snake & Thamnophis elegans & None (S5) & \\
\hline Western (Northern Pacific) rattlesnake & Crotalus viridis & None (S5) & \\
\hline${ }^{*}$ An exotic species that has become established in the state. & & \\
\hline
\end{tabular}

In most cases, breeding areas were surveyed on foot with regular stops to listen for calls. Automated call recorders were placed at two locations on FAFB (Flightline Ditch and Wildlife Area) and were recording from 2030 to 2230, 8 May to 10 Aug 2012.

Timed visual surveys were conducted during daylight hours; timing of survey varied depending on survey date and ambient temperature. Visual surveys were focused around amphibian breeding areas and included surveys for adults, larvae, and/ or eggs. Attempts were made to identify and handcapture all individuals. Road surveys were conducted in the hours around sunset and during heavy precipitation. Road surveys focused on paved roads to maximize opportunity to detect basking herpetofauna.

Dip netting was conducted in ponds during the J une survey to capture larval amphibians. Sweeps were attempted at a variety of pond depths. All captured larvae were documented and species were identified. Cover boards were placed throughout the installation (Appendix A) and were checked biweekly during each survey. Cover board placement was aimed to maximize variation in habitats. 


\section{Results}

A total of seven species, three amphibian and four reptilian, were documented at FAFB. An additional two species, the Western rattlesnake (Crotalus viridis) and Rubber boa (Charina bottae) were identified at FAFB during the time period of the surveys, although not by survey researchers. Amphibians and reptiles were documented across the majority of the southern portion of the base. Abundances of several species, including the Washington State candidate species Columbia spotted frog, appeared to be very high in certain areas. No individuals were detected at the northern (more developed) sections of the installation, likely due to lack of suitable habitat. The following sections detail information on detections of each species. Unless otherwise noted, all species information was obtained from the Washington Herp Atlas (Hallock and McAllister 2005) or NatureServe Explorer (www.natureserve.org).

\subsection{Pacific treefrog (Pseudacris regilla)}

\subsubsection{Description}

The Pacific treefrog is a small $(<5 \mathrm{~cm})$ frog from the family Hylidae. This frog is easily identified due to its conspicuous dark facial mask that extends from the nose, through the eye and tympanum, to the shoulder (Figure 2). Adults have relatively smooth skin with a dorsal body color of green to brown. Blotches or stripes frequently occur on the back of the head and down the back. Ventral surface is typically white with yellow coloration on the legs. Tree frog tadpoles are identified by prominent eyes on the margins of the head such that they appear on the side of the head when viewed from above.

Pacific treefrogs are found in a wide variety of habitats, including humandisturbed habitats. Pacific treefrogs do not have any Federal status and are considered abundant in Washington State (state rank = S5) and globally (global rank = G5). Treefrogs are the most commonly seen and heard frog species in Washington State (Hallock and McAllister 2005). 


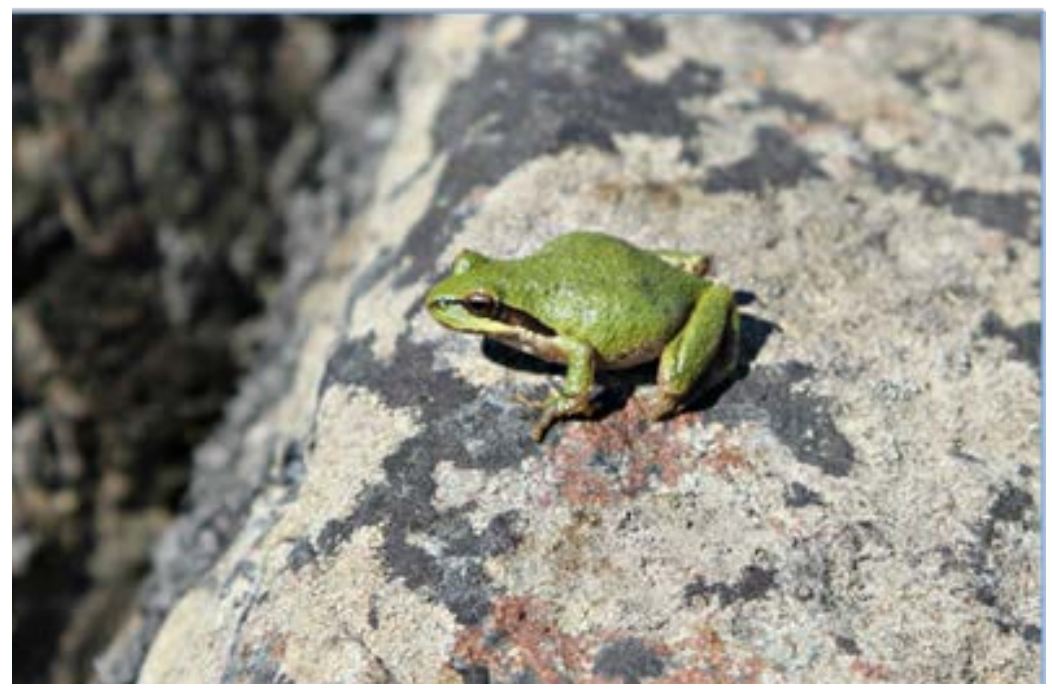

Figure 2. Pacific treefrog at FAFB.

\subsubsection{Survey results}

Pacific treefrogs were one of the most commonly detected species at FAFB. Treefrogs were found in the wildlife area, Explosive Ordnance Disposal (EOD) range, Threatened and Endangered Species (T\&E) area, Reserve Training (RT) camp, and the Munitions Storage Area (MSA) pond (Figure 3). They were found in a variety of habitats including permanent ponds, ephemeral ponds, roadside ditches, and grasslands. They were the only species calling during the May survey and aural surveys indicated that they were widespread and abundant. Pacific treefrog larvae were detected in wetlands along Pump House Road during the J une survey.

\subsection{Columbia spotted frog (Rana luteiventris)}

\subsubsection{Description}

The Columbia spotted frog is a medium to large $(42-103 \mathrm{~mm})$ frog with variable dorsal coloring (olive-brown to brick red) and black spots with light centers (Figure 4). Ventral coloring can be orange or salmon in color, particularly on hind limbs and rear of belly.

The Columbia spotted frog is highly aquatic and is rarely found far from permanent water - at the grassy margins of streams, lakes, ponds, springs, and marshes (Hodge 1976, Licht 1986). Primarily due the conservation concern of isolated populations in the southern part of its range, the Columbia spotted frog is considered a USFWS Species of Concern and a Washington State Candidate Species. 


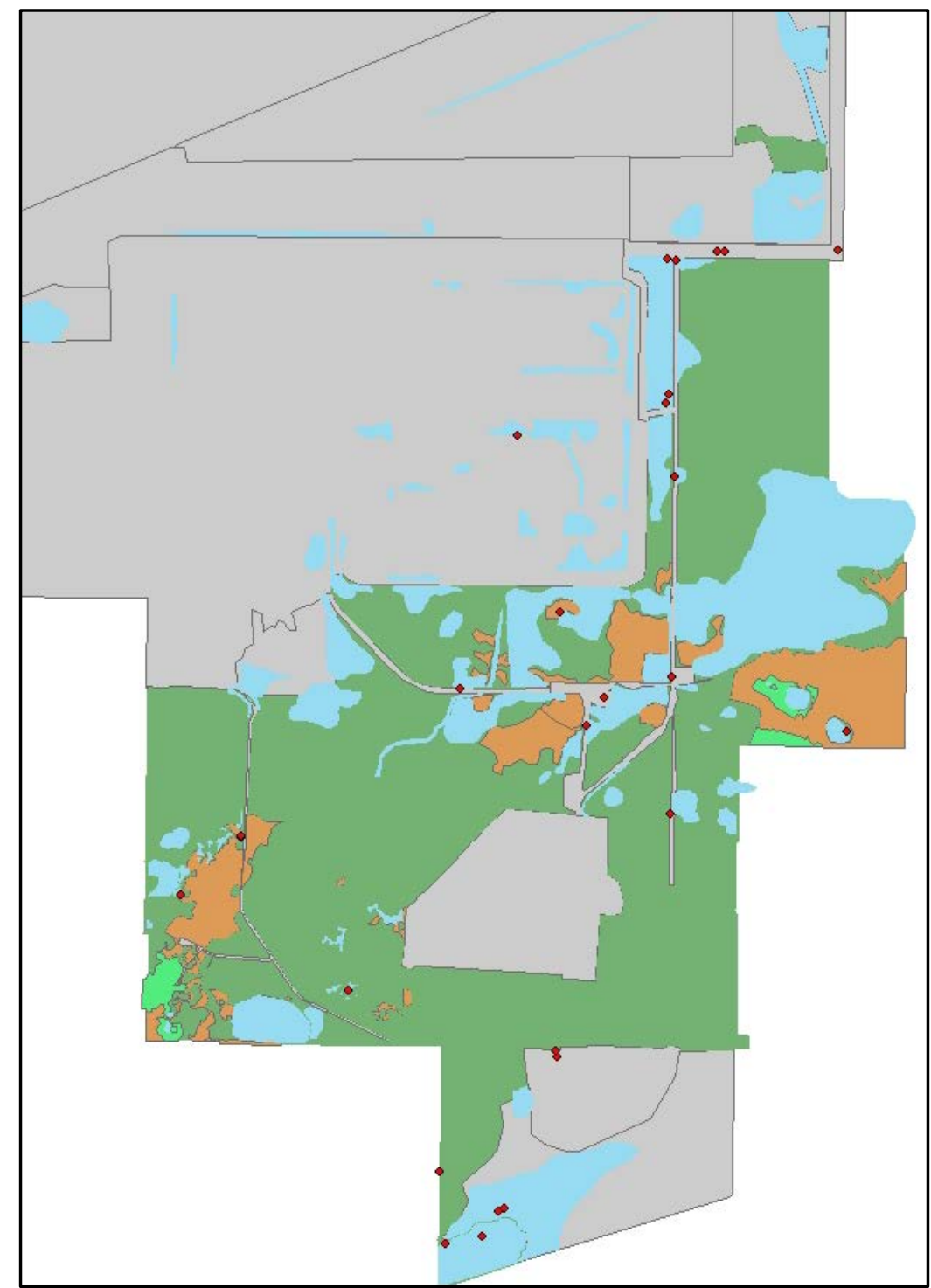

Figure 3. Pacific treefrog detections (red circles) at FAFB. Light green represents forested habitats, green represents shrublands, brown represents semi-desert (scrub-herb) habitats, blue represents wetland areas/vegetation, and grey indicates developed areas.

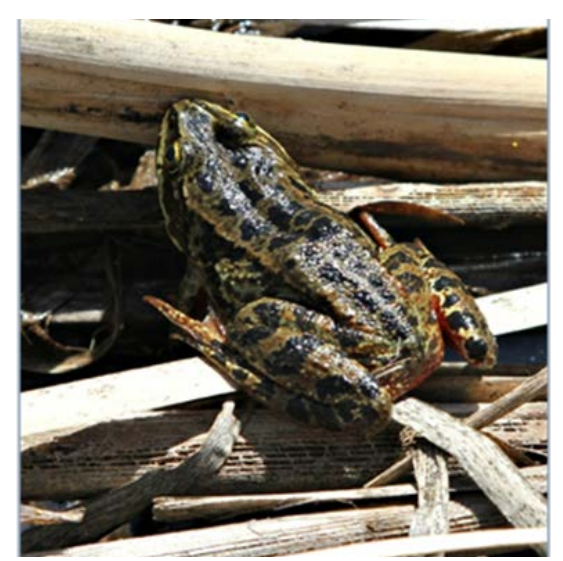

Figure 4. Columbia spotted frog at FAFB. 


\subsubsection{Survey results}

Columbia spotted frogs were the most commonly detected species at FAFB. They were found in the wildlife area, in the flightline ditch, at the MSA pond, the EOD range, and the RT camp area (Figure 5). The largest numbers of spotted frogs were detected in free-flowing ditches, but they were also found in the permanent ponds. Both adults and larvae were detected in very large numbers in the ditch paralleling the flightline. Although adults were found in several other areas, no larvae were detected south of the flightline ditch. Neither adults nor larvae were detected at the pond at UTM 451650 5272683, but a large number of post-metamorphic juveniles were found late during the J uly survey at this location.

\subsection{Western terrestrial garter snake (Thamnophis elegans)}

\subsubsection{Description}

The Western terrestrial garter snake is a medium-sized snake (max $97 \mathrm{~cm}$ length) identified by three yellow or cream colored lateral stripes on a dorsal background color of grey to brown (Figure 6). Small dark spots often occur in alternating rows between the vertebral and lateral stripes. Coloration can be variable making differentiation between garter snake species difficult. Consultation of a field guide is recommended.

In Washington State, Western terrestrial garter snakes are most often found around water sources, including along ponds, lakes, streams, and rivers (Hallock and McAllister 2009). They are typically found in grass or shrubby open areas on edges of water bodies (Hallock and McAllister 2009). T. elagans is a common, wide-ranging species and does not currently have any Federal or state conservation status.

\subsubsection{Survey results}

Western terrestrial garter snakes were the most commonly detected snake species at FAFB. A total of 13 individuals were detected and there were detections during all three survey periods (Figure 7). They were found near the flightline ditch, in the RT camp area, and at the MSA pond. They were found in association with a variety of substrates including rocks, grass, and water (two were found swimming in ponds). 


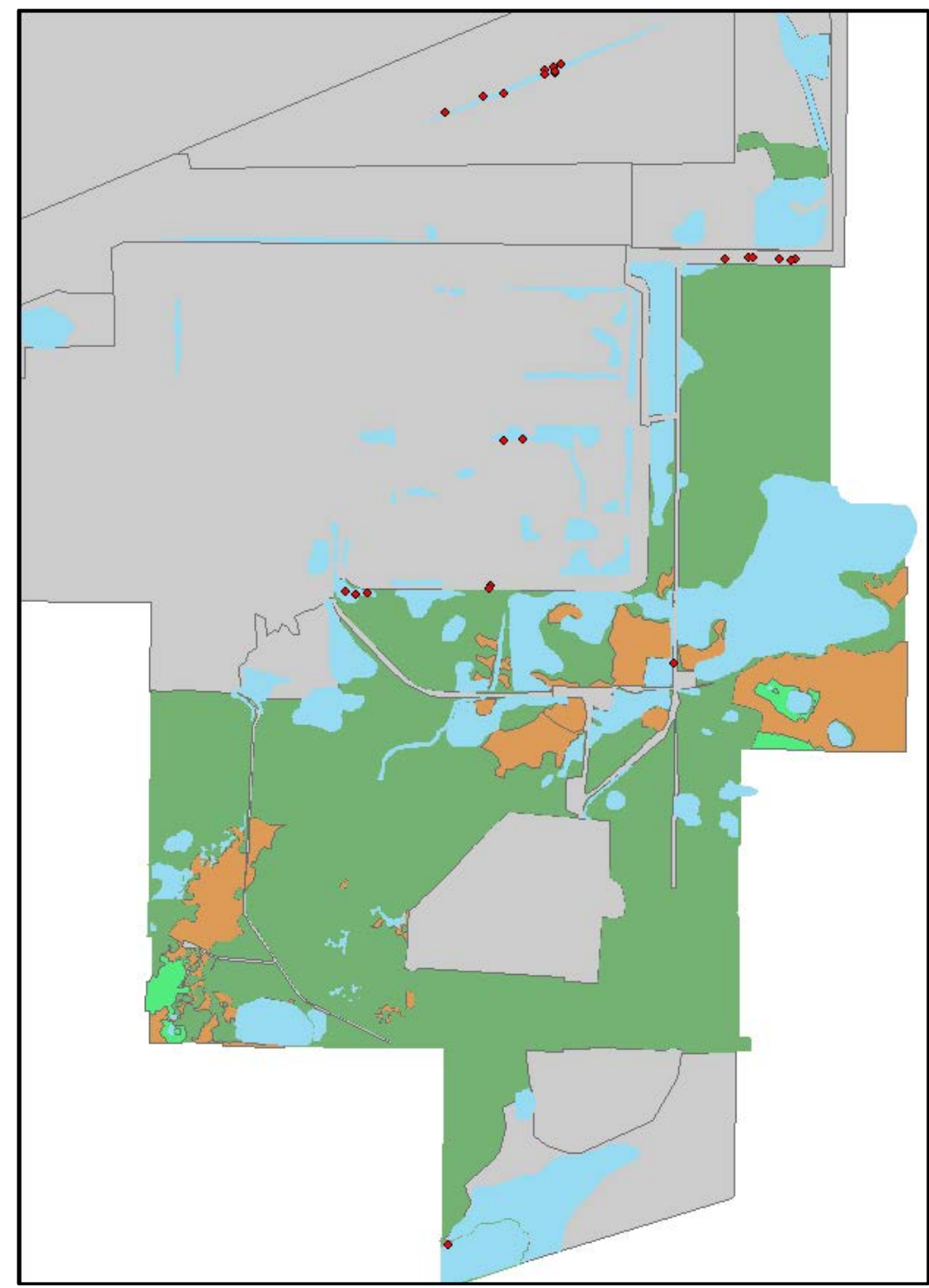

Figure 5. Columbia spotted frog detections (red circles ) at FAFB. Light green represents forested habitats, green represents shrublands, brown represents semi-desert (scrub-herb) habitats, blue represents wetland areas/vegetation, and grey indicates developed areas.

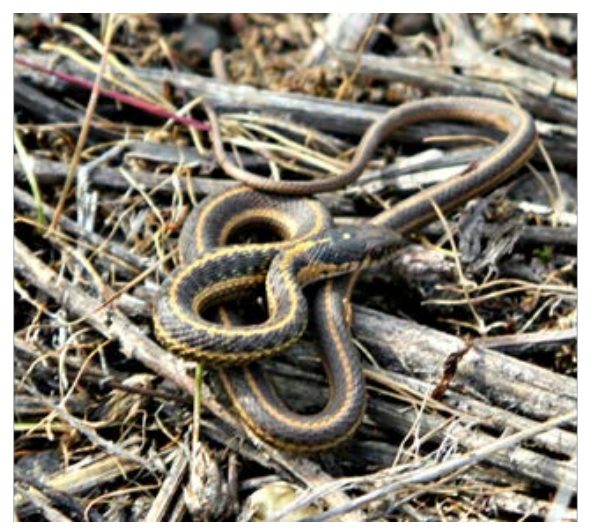

Figure 6. Western terrestrial garter snake at FAFB. 


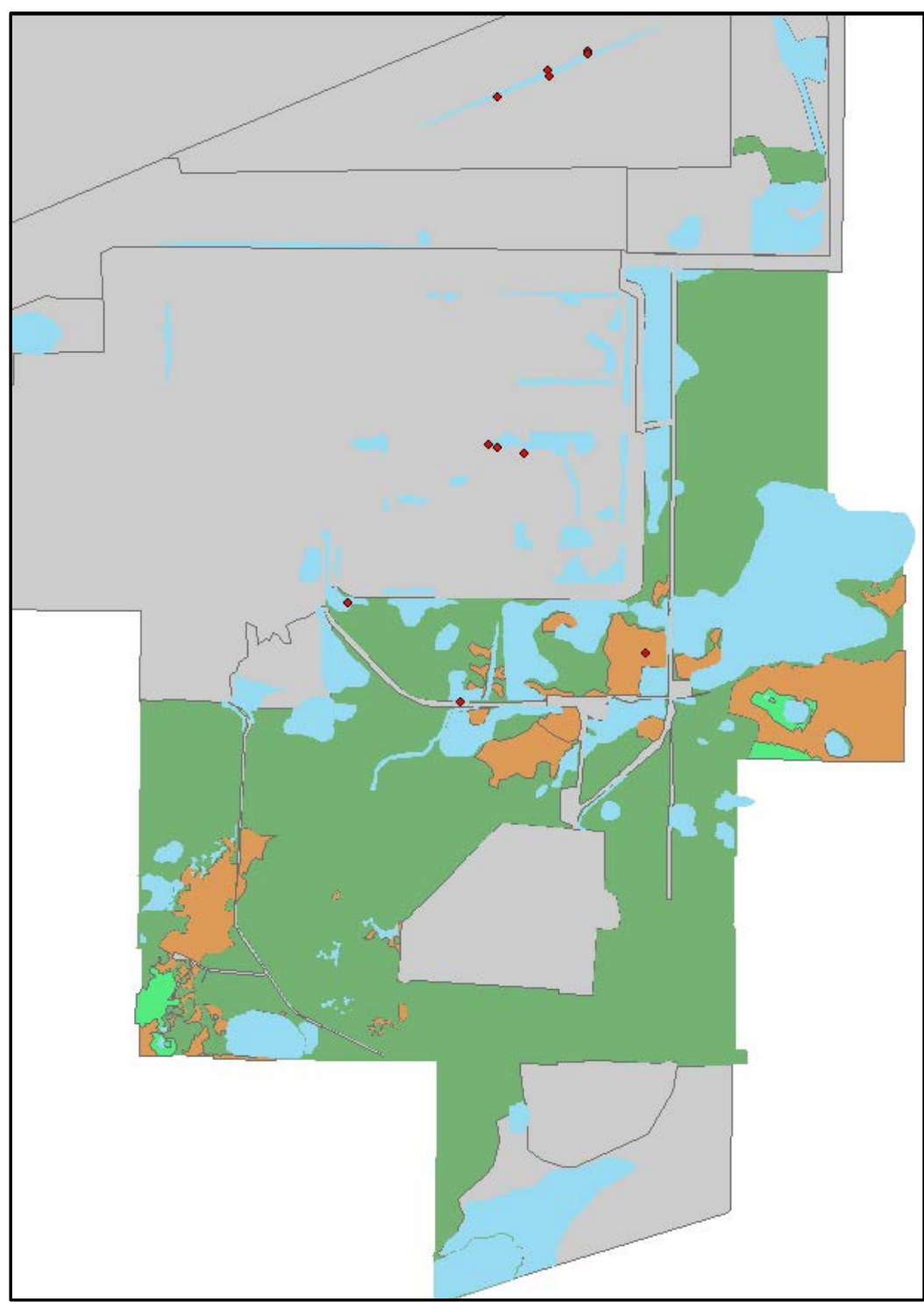

Figure 7. Western terrestrial garter snake detections (red circles) at FAFB. Light green represents forested habitats, green represents shrublands, brown represents semi-desert (scrub-herb) habitats, blue represents wetland areas/vegetation, and grey indicates developed areas.

\subsection{Valley (common) garter snake (Thamnophis sirtalis)}

\subsubsection{Description}

Similar to T. elegans, the Valley garter snake is a medium-sized snake with three dorsal stripes. In eastern Washington State, the Valley garter snake is identified by distinct red blotches on the sides of the body (Figure 8). Again, because of overlap in characteristics among Thamnophis species, a field guide should be used to confirm identification. 


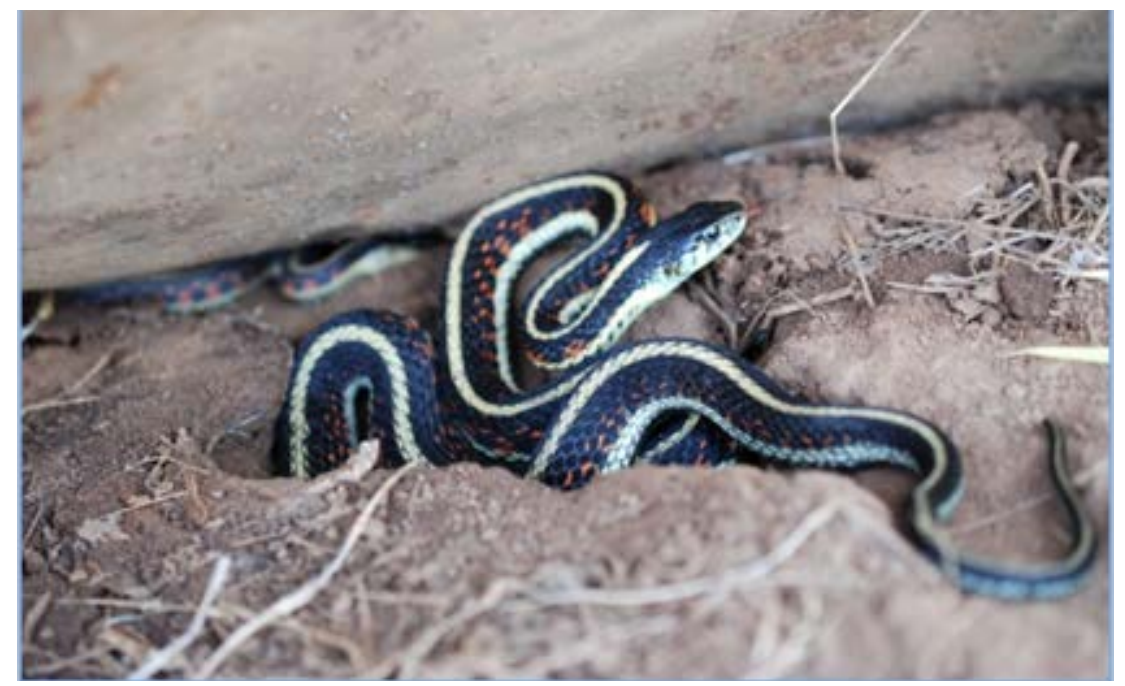

Figure 8. Valley garter snake at FAFB.

Valley garter snakes are often found near water bodies, including wetlands, ponds, creeks, and rivers. They are typically in open areas near water such as forest opening, grasslands, and or shrubby areas. Populations are apparently secure and do have any state or Federal conservation status.

\subsubsection{Survey results}

Three Valley garter snakes were identified at FAFB, one during the May survey and two during the J uly survey. The individual encountered during the May survey was found in the T\&E area. The two snakes detected during the J uly survey were found together under a piece of metal refuse in the EOD range area (Figures 8 and 9).

\subsection{Racer (Coluber constrictor)}

\subsubsection{Description}

Racers are medium- to large-sized (max $190 \mathrm{~cm}$ length) colubrids with smooth (unkeeled) scales and a solid dorsal coloring (Figure 10) of brown to olive. Ventral coloring can range from yellow to cream. Racers are very alert, agile snakes that typically flee when encountered. They will raise their heads above ground to survey surroundings.

Racers are found in a wide variety of habitats including forests, open areas, and habitat edges. When inactive, racers will hide underground or under surface cover. Racers are widespread and abundant and so have no state or Federal conservation status. 


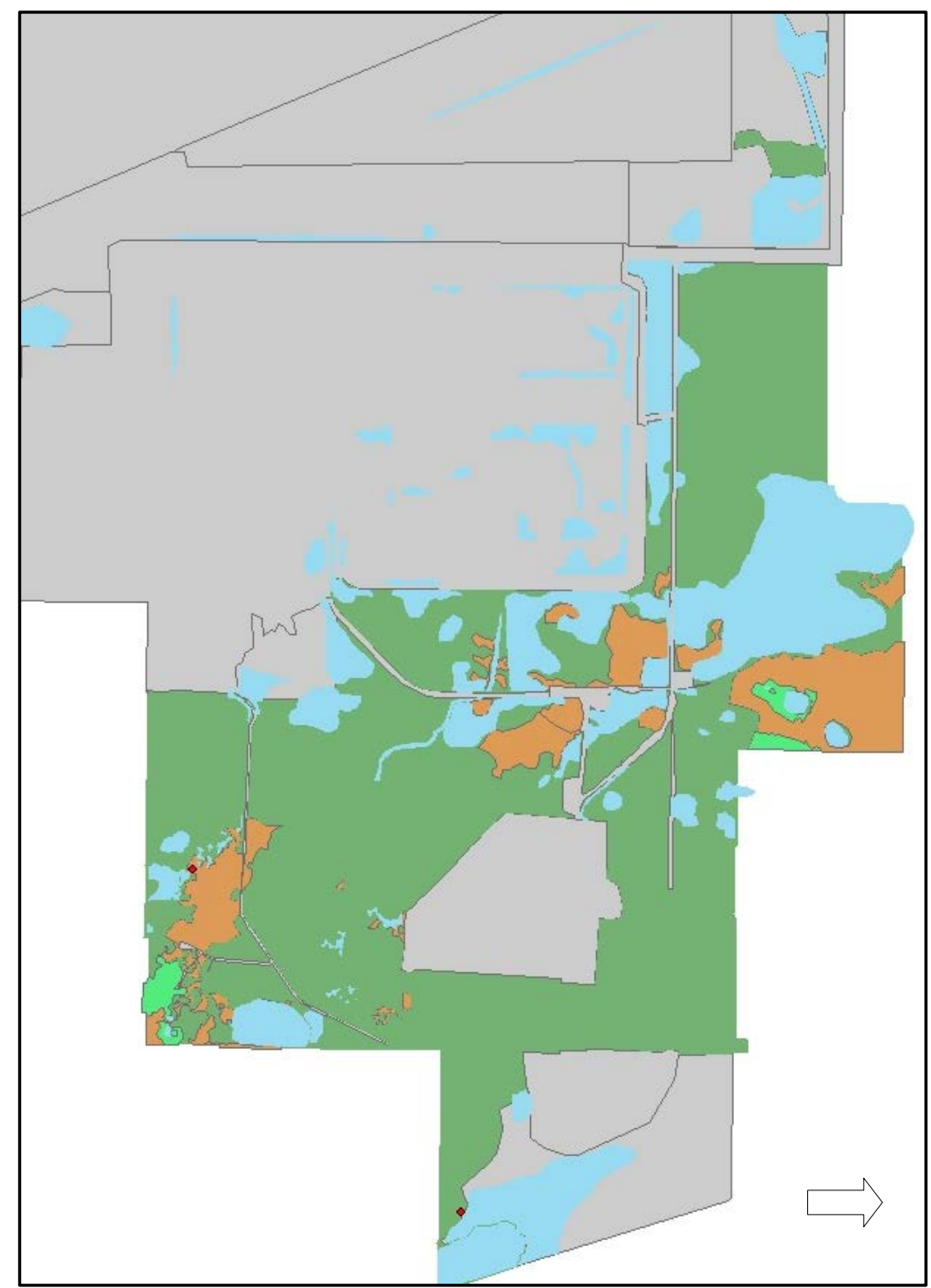

Figure 9. Valley garter snake (red circles) at FAFB. Light green represents forested habitats, green represents shrublands, brown represents semi-desert (scrub-herb) habitats, blue represents wetland areas/vegetation, and grey indicates developed areas.

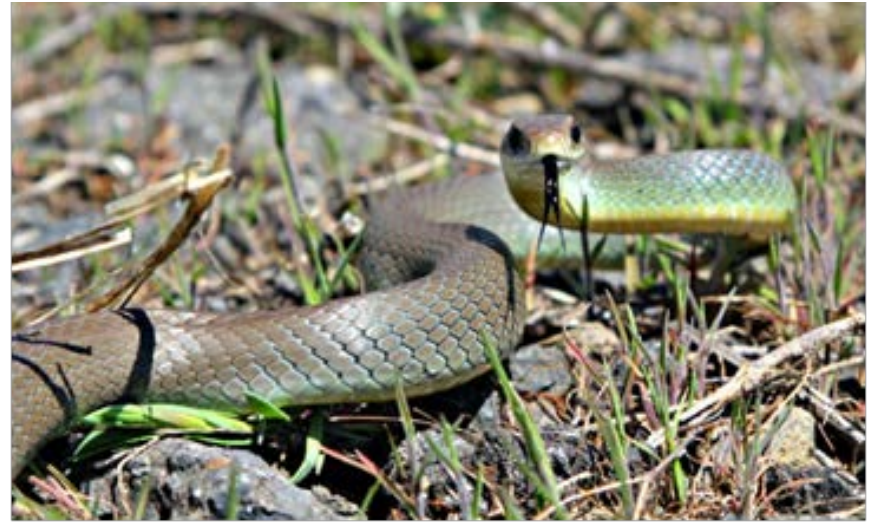

Figure 10. Racer at FAFB. 


\subsubsection{Survey results}

Two racers were detected on FAFB, one just outside the T\&E area under a plywood board during the May survey and the other found during the J une survey on the road (DOA) bordering the wildlife area (Figure 11).

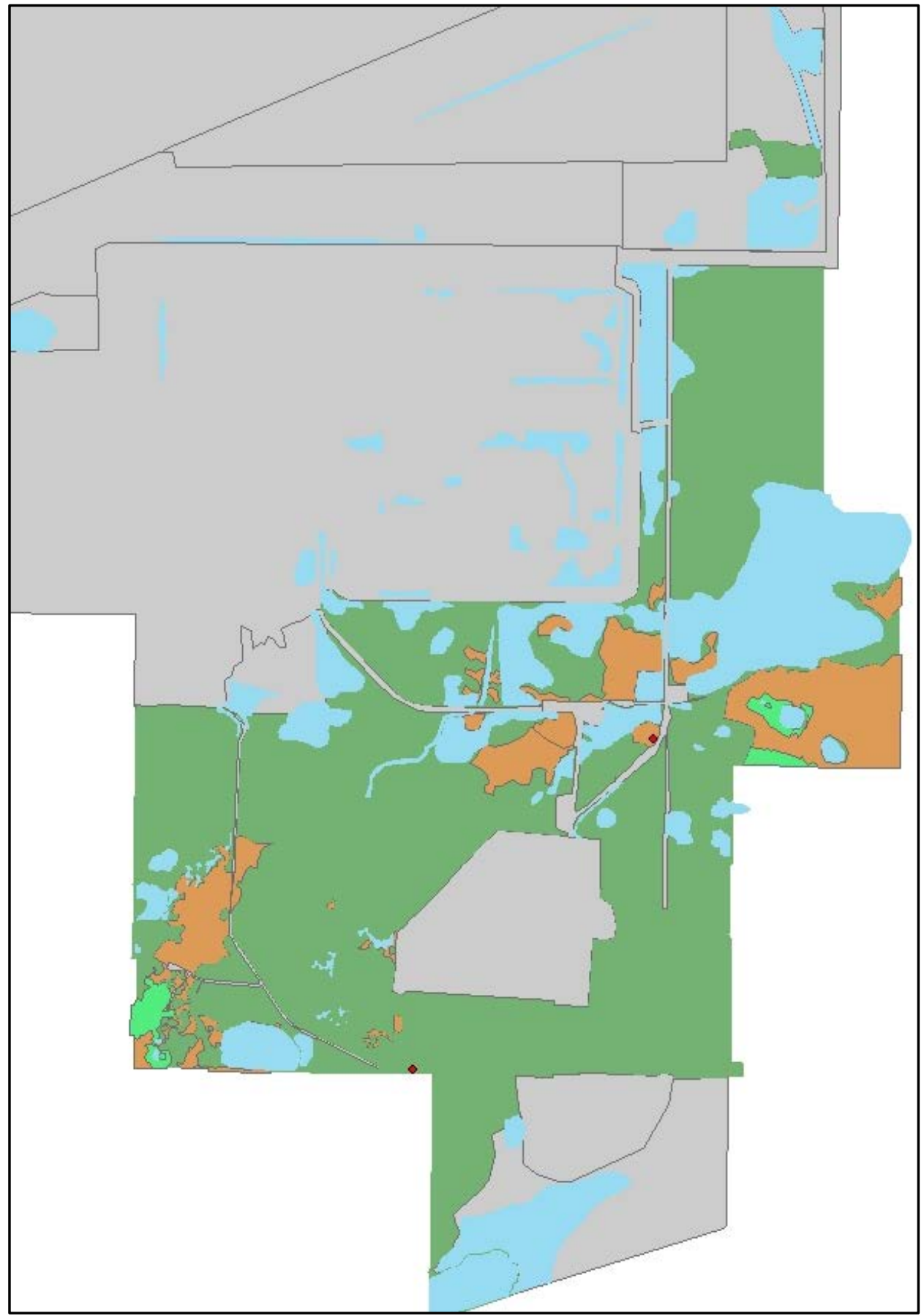

Figure 11. Racer detections (red circles) at FAFB. Light green represents forested habitats, green represents shrublands, brown represents semi-desert (scrub-herb) habitats, blue represents wetland areas/vegetation, and grey indicates developed areas. 


\subsection{Long-toed salamander (Ambystoma macrodactylum)}

\subsubsection{Description}

The Long-toed salamander is a medium-sized salamander with dark grey to black dorsal coloring and an irregular, often broken, yellow-green dorsal stripe (Figure 12). They commonly have blue or white speckling on the sides of the body. As their common name implies, this species has an unusually long fourth hind toe.

Long-toed salamanders are found in a variety of habitats, including urban and disturbed habitats. Breeding typically occurs in seasonal pools that are absent fish. While active in the spring, adults often seek refuge under structures that maintain moisture, including rocks, logs, and loose bark (Hallock and McAllister 2005). Long-toed salamanders are widespread and common, and have no state or Federal conservation status.

\subsubsection{Survey results}

A total of six Long-toed salamanders were detected on FAFB, all during the May survey. The majority of detections (four of the six) were from the T\&E area, primarily under rocks near the vernal pools. One was found under a plywood board in the EOD area and one was found under a rock just west of the wildlife area (Figure 13).

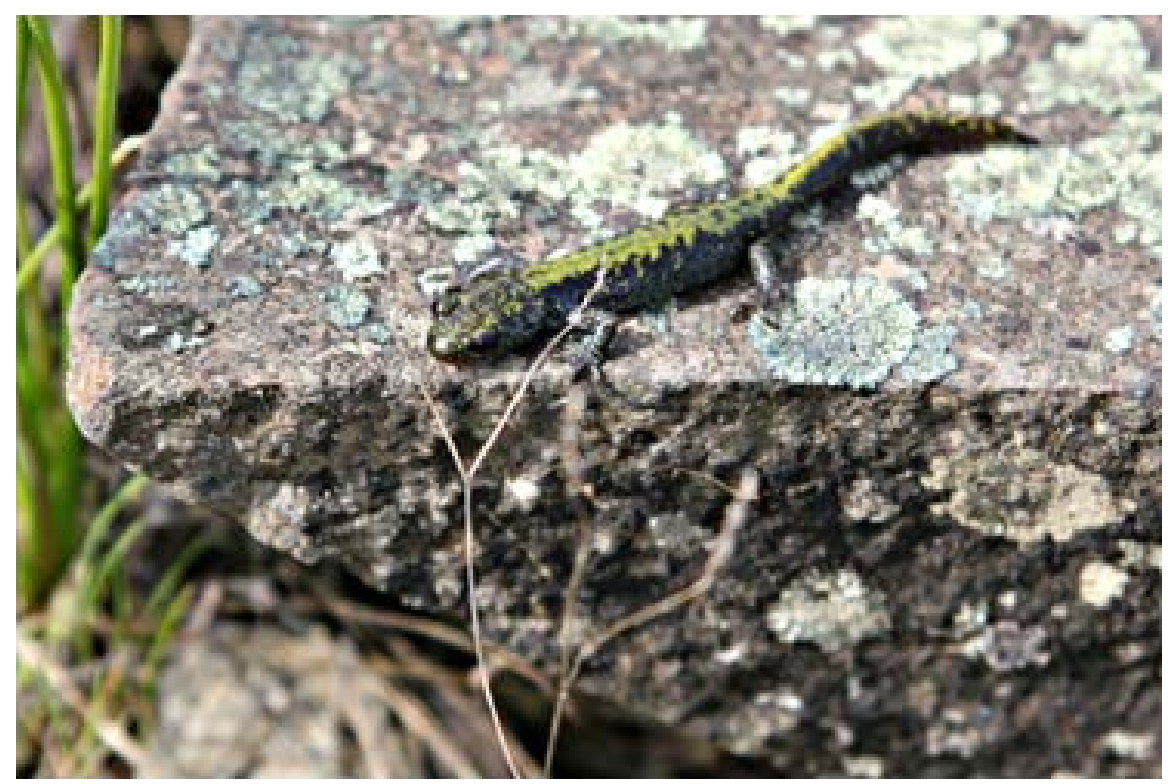

Figure 12. Long-toed salamander at FAFB. 


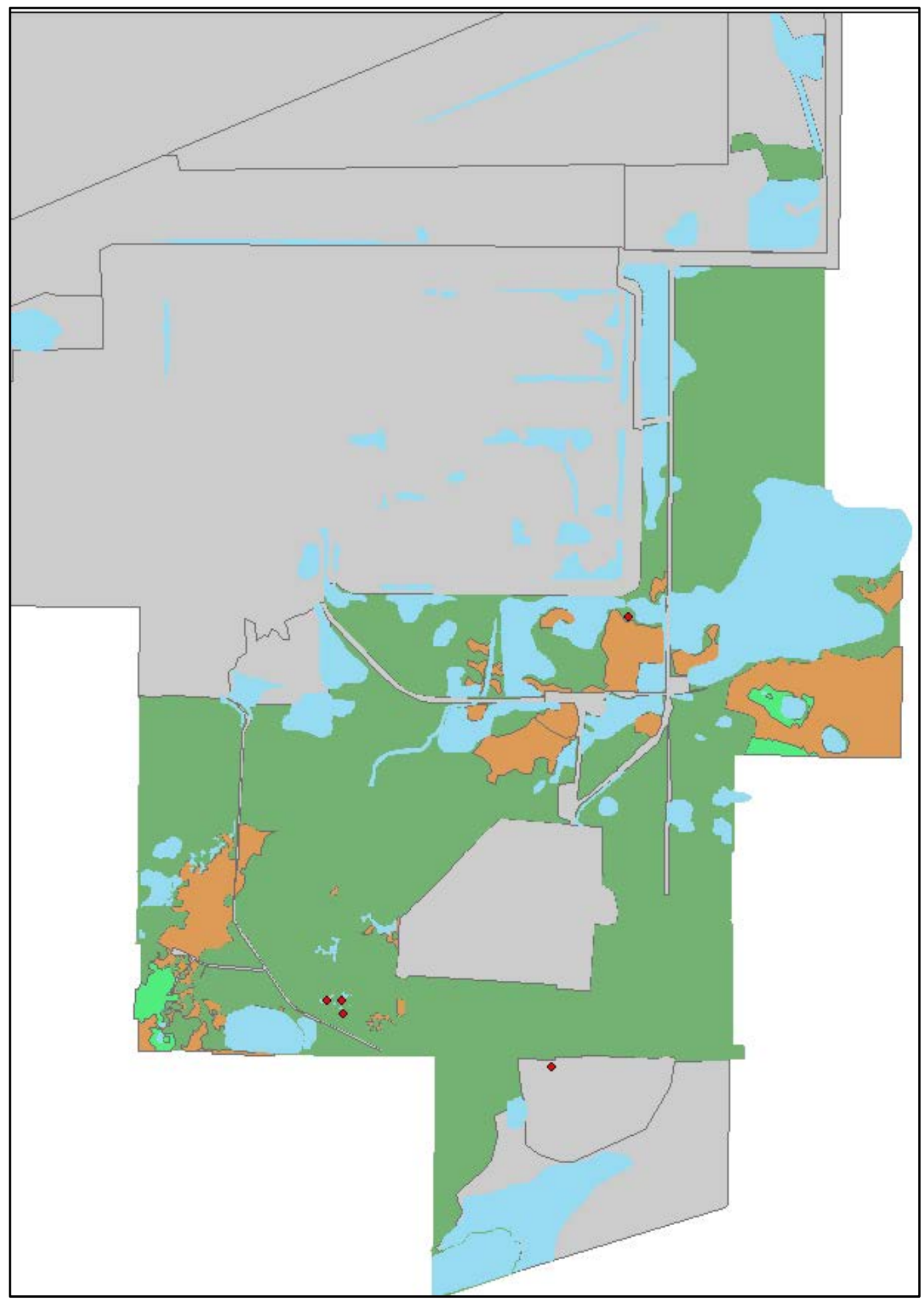

Figure 13. Long-toed salamander detections (red circles) at FAFB. Light green represents forested habitats, green represents shrublands, brown represents semi-desert (scrub-herb) habitats, blue represents wetland areas/vegetation, and grey indicates developed areas. 


\subsection{Painted turtle (Chrysemys picta)}

\subsubsection{Description}

The Painted turtle is a medium-sized aquatic turtle with a dark olive, brown or black carapace, yellow streaking on head, and bright red markings on plastron (Figures 14 and 15). Coloration of the plastron fades with age. This species is found primarily in aquatic habitats with a preference for habitats with muddy sediment and abundant aquatic vegetation. Aquatic habitats include lakes, ponds, wetlands, and slow flowing areas of rivers. Individuals are often detected with heads emerging from water and will often submerge under water when approached. This species is common and widespread with no state or Federal conservation status.

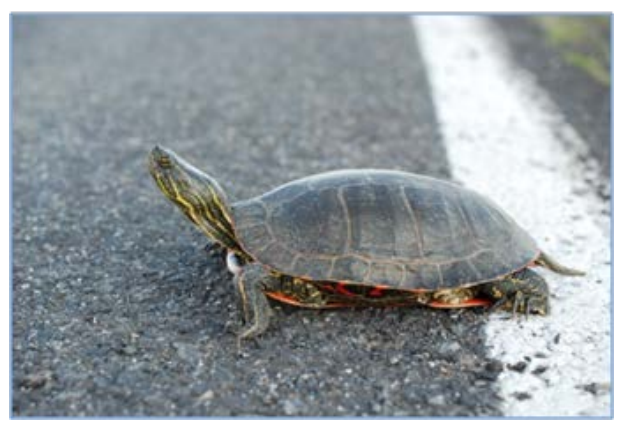

Figure 14. Painted turtle at FAFB.

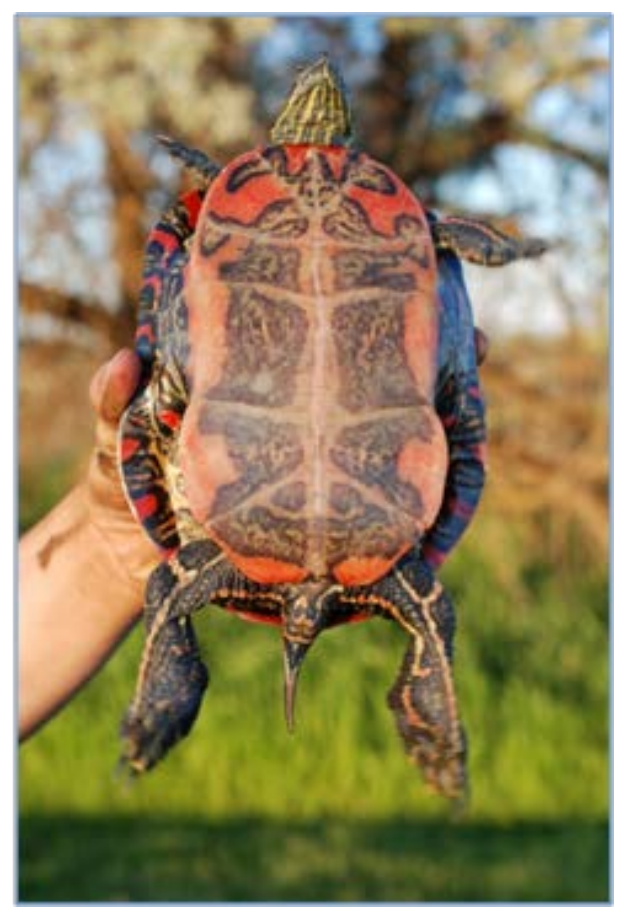

Figure 15. Bright red markings on plastron of Painted turtle at FAFB. 


\subsubsection{Survey results}

Fifteen individual Painted turtles were detected at FAFB during all survey periods. The majority of detections occurred at the MSA pond although they were also detected in the lagoon near the flightline and, on one occasion, on the paved road bordering the wildlife area (Figure 16).

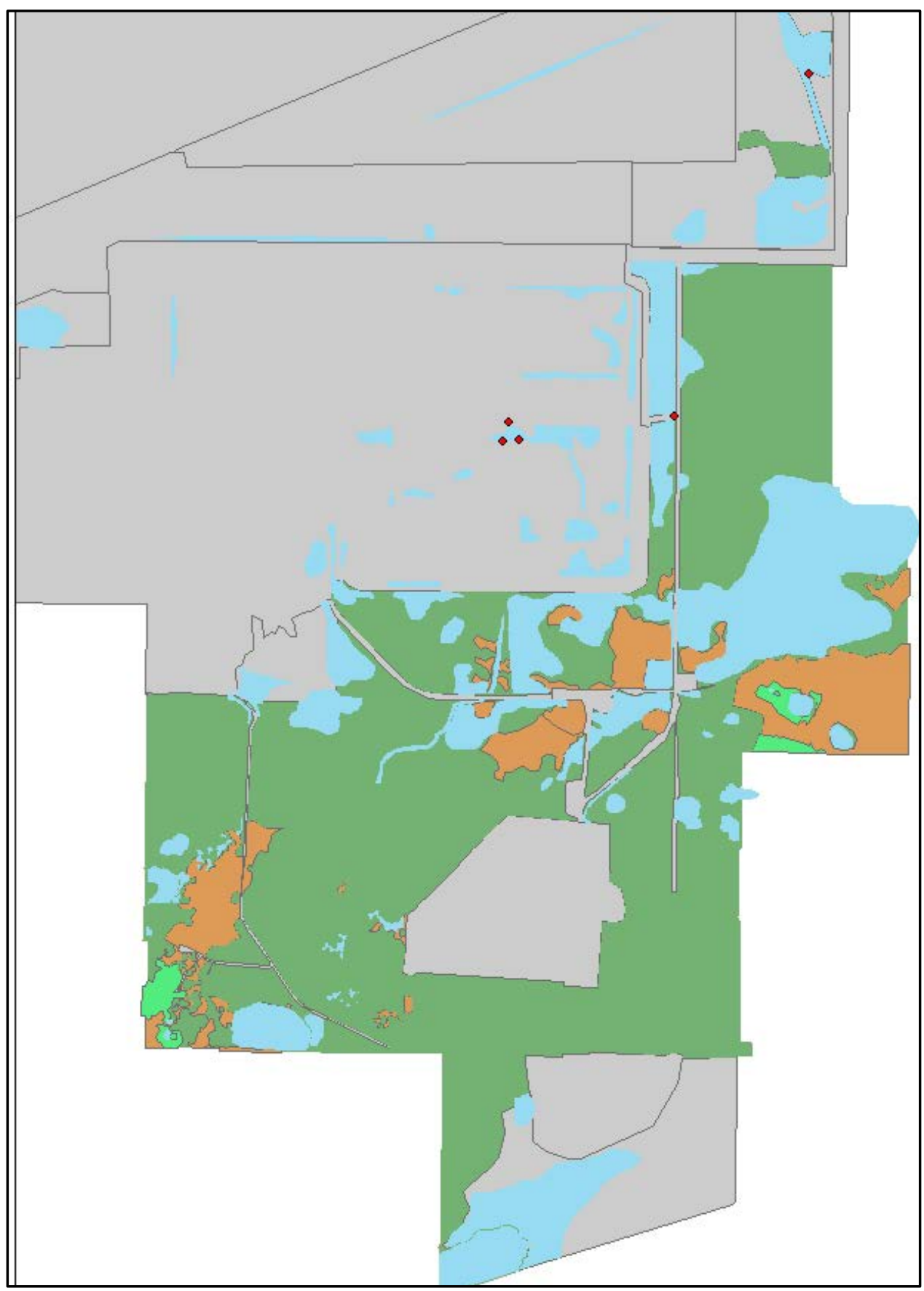

Figure 16. Painted turtle detections (red circles) at FAFB. Light green represents forested habitats, green represents shrublands, brown represents semi-desert (scrub-herb) habitats, blue represents wetland areas/vegetation, and grey indicates developed areas. 


\section{Discussion}

Although a limited number of species were detected on FAFB, those species found present appear to have abundant populations. Of particular note, the Columbia spotted frog, a state candidate species, was detected in very large numbers on the base, particularly in the constructed ditch within the flightline area. Numerous adults (up to 45 per 2-hour survey) were encountered in this ditch along with innumerable larvae. Columbia spotted frogs were also found in roadside ditches elsewhere on the base, perhaps indicating a preference for this habitat type. Because this is a species of conservation concern, presence of this species in ditches may be of consideration in ditch vegetation management. Mowing does not seem to deleteriously affect a closely related species, the Oregon spotted frog (Rana pretiosa), and may in fact improve habitats (Cushman and Pearl 2007). However, timing of mowing should be considered since mowing blades and heavy equipment can harm individuals (Sas et al. 2006). Adults and metamorphs were detected in one recently mowed roadside ditch on FAFB. However, another roadside ditch that had numerous adults in the J une survey (prior to mowing) did not have any following mowing; this suggests that timing of mowing may influence metamorph success or use.

Although the majority of adult spotted frogs were found in ditches, it is interesting to note that a large number of metamorphs were found within a pond (at UTM 451650 5272683) that had not had any prior evidence of amphibian use. This pond had very little aquatic vegetation in earlier surveys, making it unsuitable for breeding, but had a near complete covering of emergent vegetation during the J uly survey. Use of different habitats for breeding and postmetamorphic stages, in association with herbaceous wetland vegetation, is common for this genus (McAllister and Leonard 1997). This suggests that this population would benefit from maintenance of both free-flowing streams (constructed or natural) and ponds, within close proximity.

Pacific treefrogs were also frequently detected on FAFB although there appeared to be divergence in preferred habitats between the Columbia spotted frog and the Pacific treefrog. Whereas Columbia spotted frogs were found in largest numbers in free-flowing ditches, Pacific treefrogs were detected most often in the permanent and seasonal wetland areas, particularly the ponds and wetlands near the wildlife area and in the far southern 
portion of the EOD area. Pacific treefrogs were most often identified through aural surveys. (This species was very vocal during the May survey.) Although this would indicate breeding efforts in these ponds, the abundance of emergent aquatic vegetation, particularly reeds, made it difficult to perform a dip net survey for larvae to provide some measure of abundance. However, a small number of treefrog larvae were detected near the wildlife area in a wetland site unusually free of vegetation, signifying successful breeding.

Western terrestrial garter snakes, Painted turtles, and Long-toed salamanders were also regularly detected on the base, indicating abundant populations. Racers and common garter snakes were also detected. All of these species are common and widespread with little conservation concern.

An additional 11 species that were identified as potentially occurring on FAFB, based on range maps, were not detected during the surveys. Two of these species, the Western rattlesnake and Rubber boa, were identified on the base, although not by survey personnel. Although lack of detections during surveys could indicate small populations on the base, many of these species are very cryptic and so have an increased probability of evading detection. For many of these species, cover board arrays would likely be a useful method of detection. Although this survey did not detect any herpetofauna using the cover boards during these surveys, cover boards often need to remain in place for a length of time before receiving herpetofaunal use. It is recommended that FAFB Natural Resource personnel occasionally monitor the cover boards on the installation and update the herpetofaunal species list accordingly. 


\section{Conclusions and Recommendations}

\subsection{Conclusions}

This work surveyed herpetofaunal populations on FAFB and detected a limited number of species that appear to have abundant populations at that site. The Columbia spotted frog, a state candidate species, was detected in very large numbers on the base. Pacific treefrogs were also frequently detected on FAFB. Western terrestrial garter snakes, Painted turtles, and Long-toed salamanders were also regularly detected on the base, indicating abundant populations. Racers and common garter snakes were also detected. All of these species are common and widespread with little conservation concern.

An additional 11 species were identified as potentially occurring on FAFB, based on range maps, but were not detected during the surveys. Two of these species, the Western rattlesnake and Rubber boa, were identified on the base, although not by survey personnel.

\subsection{Recommendations}

The Columbia spotted frog, a state candidate species, was detected in very large numbers on the base, particularly in the constructed ditch within the flightline area. Pacific treefrogs were also frequently detected on FAFB although there appeared to be divergence in preferred habitats between the Columbia spotted frog and the Pacific treefrog. Columbia spotted frogs were also found in roadside ditches elsewhere on the base, perhaps indicating a preference for this habitat type. Because this is a species of conservation concern, presence of this species in ditches may be of consideration in ditch vegetation management. Mowing does not seem to deleteriously affect a closely related species, the Oregon spotted frog (Rana pretiosa), and may in fact improve habitats. However, timing of mowing should be considered since mowing blades and heavy equipment can harm individuals. Adults and metamorphs were detected in one recently mowed roadside ditch on FAFB. However, another roadside ditch that had numerous adults in the J une survey (prior to mowing) did not have any following mowing. This suggests that timing of mowing may influence metamorph success or use. 
Although the majority of adult spotted frogs were found in ditches, it is interesting to note that a large number of metamorphs were found within a pond (at UTM 451650 5272683) that had not had any prior evidence of amphibian use. This pond had very little aquatic vegetation in earlier surveys, making it unsuitable for breeding, but had a near complete covering of emergent vegetation during the J uly survey. Since the use of different habitats for breeding and post-metamorphic stages, in association with herbaceous wetland vegetation, is common for this genus, this population may benefit from maintenance of both free-flowing streams (constructed or natural) and ponds, within close proximity.

An additional 11 species that were identified as potentially occurring on FAFB, based on range maps, were not detected during the surveys. Two of these species, the Western rattlesnake and Rubber boa, were identified on the base, although not by survey personnel. Although lack of detections during surveys could indicate small populations on the base, many of these species are very cryptic and so have an increased probability of evading detection. For many of these species, cover board arrays would likely be a useful method of detection. Although this survey did not detect any herpetofauna using the cover boards during these surveys, cover boards often need to remain in place for a length of time before receiving herpetofaunal use. It is recommended that FAFB Natural Resource personnel occasionally monitor the cover boards on the installation and update the herpetofaunal species list accordingly. 


\section{Acronyms and Abbreviations}

$\begin{array}{ll}\text { Term } & \text { Definition } \\ \text { ANSI } & \text { American National Standards Institute } \\ \text { CEERD } & \text { US Army Corps of Engineers, Engineer Research and Development Center } \\ \text { CERL } & \text { Construction Engineering Research Laboratory } \\ \text { DOA } & \text { Dead on Arrival } \\ \text { DoD } & \text { US Department of Defense } \\ \text { EOD } & \text { Explosive Ordnance Disposal } \\ \text { EPA } & \text { Environmental Protection Agency } \\ \text { ERDC } & \text { Engineer Research and Development Center } \\ \text { FAFB } & \text { Fairchild Air Force Base } \\ \text { INRMP } & \text { Integrated Natural Resources Management Plans } \\ \text { ISE } & \text { Installation Support Directorate, Environmental Division } \\ \text { IUCN } & \text { International Union for Conservation of Nature and Natural Resources } \\ \text { MSA } & \text { Munitions Storage Area } \\ \text { NSN } & \text { National Supply Number } \\ \text { OACSIM } & \text { Office of the Assistant Chief of Staff for Installation Management } \\ \text { OMB } & \text { Office of Management and Budget } \\ \text { RT } & \text { Reserve Training } \\ \text { SAR } & \text { Same As Report } \\ \text { SF } & \text { Standard Form } \\ \text { TR } & \text { Technical Report } \\ \text { US } & \text { United States } \\ \text { USA } & \text { United States of America } \\ \text { USDA } & \text { US Department of Agriculture } \\ \text { USFWS } & \text { US Fish and Wildlife Service } \\ \text { UTM } & \text { Universal Transverse Mercator } \\ \text { WWW } & \text { World Wide Web } \\ & \end{array}$




\section{References}

Cushman, K. A., and C. A. Pearl. 2007. A conservation assessment for the Oregon Spotted Frog (Rana pretiosa). USDA Forest Service Region 6 Report.

Fairchild Air Force Base (FAFB). May 2011. Integrated natural resources management plan update: Official draft. FAFB, WA: Air Mobility Command, 92 ${ }^{\text {nd }}$ Wing, http://www.fairchild.af.mil/shared/media/document/AFD-110608-031.pdf

Gibbons, J . W., D. E. Scott, T. J . Ryan, K. A. Buhlman, T. D. Tuberville, B. S. Mettis, J. L. Greene, T. Mills, Y. Leiden, S. Poppy, and C. T. Winne. 2000. The global decline of reptiles, déjà vu amphibians. BioScience. 50: 653-666

Hallock, L. A., and K. R. McAllister. 2005. Washington herp atlas. Website, http://www1.dnr.wa.gov/nhp/refdesk/herp/

Heyer, W. R., M. A. Donnelly, R. W. McDiarmid, L. C. Hayek, and M. S. Foster. 1994. Measuring and monitoring biological diversity: Standard methods for amphibians. Washington, DC: Smithsonian Institute Press.

International Union for Conservation of Nature and Natural Resources (IUCN). 2011. IUCN red list of threatened species. Version 2011.2, www.iucnredlist.org

McAllister, K. R., and W. P. Leonard. 1997. Washington state status report for the Oregon spotted frog. Olympia, WA: Washington Department of Fish and Wildlife.

Omernik, J . M. 1987. Ecoregions of the conterminous United States. Map (scale 1:7,500,000). Annals of the Association of American Geographers 77(1):118-125.

Sas, I., S. Covaciu-Marcov, E. Kovacs, N. Radu, A. Toth, and A. Popa. 2006. The populations of Rana arvalis Nills, 1842 from the Ier Valley (The Western Plain, Romania): Present and future. Northwestern J ournal of Zoology 2: 1-16.

Stebbins, R. C. 2003. A field guide to western amphibians and reptiles. 3d ed. Boston, MA: Houghton Mifflin Company.

Stuart, S., J. S. Chanson, N. A. Cox, B. E. Young, A. S. L. Rodrigues, D. L. Fishman, and R. W. Waller. 2004. Status and trends of amphibian declines and extinctions worldwide. Science 306: 1783-1786.

NatureServe. 2012. NatureServe explorer. Website, www.natureserve.org

US Environmental Protection Agency (USEPA). 2012. Western Ecology Division. Web page. Accessed 15 November 2012, http://www.epa.gov/wed/pages/ecoregions.htm 


\section{Appendix A: Cover Board Locations at Fairchild Air Force Base, WA}

Table A1. Cover board locations at FAFB.

\begin{tabular}{|c|c|c|}
\hline Number & Easting & Northing \\
\hline 1 & 452938 & 5273356 \\
\hline 2 & 452927 & 5273103 \\
\hline 3 & 452966 & 5272912 \\
\hline 4 & 452763 & 5272427 \\
\hline 5 & 452509 & 5272158 \\
\hline 6 & 451769 & 5271486 \\
\hline 7 & 451604 & 5271534 \\
\hline 8 & 451466 & 5271712 \\
\hline 9 & 452398 & 5272239 \\
\hline 10 & 452054 & 5272387 \\
\hline 11 & 451641 & 5272685 \\
\hline 12 & 452953 & 5276003 \\
\hline 13 & 452363 & 5275851 \\
\hline 14 & 452142 & 5275844 \\
\hline 15 & 452092 & 5275878 \\
\hline 16 & 452050 & 5275978 \\
\hline 17 & 451318 & 5272038 \\
\hline 18 & 451881 & 5272161 \\
\hline 19 & 451820 & 5271658 \\
\hline 20 & 451987 & 5271005 \\
\hline 21 & 451187 & 5271847 \\
\hline 22 & 452061 & 5272703 \\
\hline & & \\
\hline
\end{tabular}




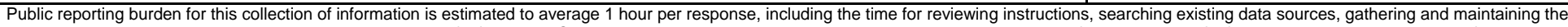

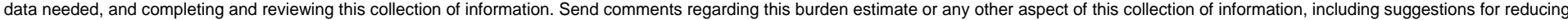

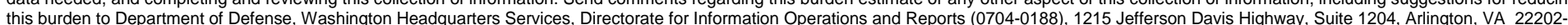

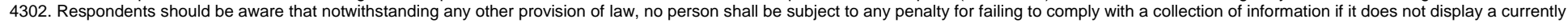
valid OMB control number. PLEASE DO NOT RETURN YOUR FORM TO THE ABOVE ADDRESS.
1. REPORT DATE (DD-MM-YYYY) 10-05-2013

\section{REPORT TYPE} Final

\section{TITLE AND SUBTITLE}

Reptiles and Amphibians of Fairchild Air Force Base, WA
3. DATES COVERED (From - To)

5a. CONTRACT NUMBER

5b. GRANT NUMBER

5c. PROGRAM ELEMENT

5d. PROJECT NUMBER

6. AUTHOR(S)

J inelle H. Sperry 5e. TASK NUMBER

5f. WORK UNIT NUMBER

8. PERFORMING ORGANIZATION REPORT NUMBER

ERDC/ CERL TR-13-5

US Army Engineer Research and Development Center (ERDC)

Construction Engineering Research Laboratory (CERL)

PO Box 9005,

Champaign, IL 61826-9005

\section{SPONSORING I MONITORING AGENCY NAME(S) AND ADDRESS(ES)}

Fairchild Air Force Base (FAFB)

92nd Civil Engineer Squadron

100 West Ent Street Suite 155

Fairchild AFB, WA 99011

10. SPONSOR/MONITOR'S ACRONYM(S)

FAFB

11. SPONSOR/MONITOR'S REPORT NUMBER(S)

\section{DISTRIBUTION / AVAILABILITY STATEMENT}

Approved for public release; distribution is unlimited.

\section{SUPPLEMENTARY NOTES}

\section{ABSTRACT}

Many reptile and amphibian (collectively termed "herpetofauna”) populations are declining at a precipitous rate. Globally, nearly 30\% of herpetofauna are considered endangered or at risk of extinction. Department of Defense (DoD) installations likely serve as refuges of intact critical habitat for herpetofaunal species, as they do for many other taxa. As more herpetofaunal species become a conservation concern, it becomes increasingly important for DoD land managers to document the species that currently exist on their lands and, through proactive management, avoid potential conflicts between conservation measures and military training. The onus for the protection and long-term population viability of threatened and endangered herpetofaunal species will likely fall in the hands of the installations themselves and will depend on installation management practices. The first step in developing a process to successfully manage herpetofaunal species is to survey their populations on DoD installations. This work surveyed herpetofaunal populations on Fairchild Air Force Base and extrapolated guidelines for species management from the survey results.

\section{SUBJECT TERMS}

Fairfield AFB, herpetofauna, natural resources management, TES, survey

\section{SECURITY CLASSIFICATION OF:}

\begin{tabular}{l}
\hline a. REPORT \\
Unclassified
\end{tabular}

NSN 7540-01-280-5500

\section{b. ABSTRACT}

$$
\text { Unclassified }
$$

\section{c. THIS PAGE}

Unclassified

\begin{tabular}{|c|}
$\begin{array}{c}\text { 17. LIMITATION } \\
\text { OF ABSTRACT } \\
\text { SAR }\end{array}$ \\
\hline
\end{tabular}

\begin{tabular}{|c|c|} 
18. NUMBER \\
OF PAGES
\end{tabular}

19a. NAME OF RESPONSIBLE PERSON

19b. TELEPHONE NUMBER (include area code) 